Letrônica, Porto Alegre, v. 7, n. 2, p. 547-564, jul./dez., 2014

\title{
ACENTO SECUNDÁRIO E EPÊNTESE VOCÁLICA NO PORTUGUÊS DO SUL DO BRASIL
}

\author{
SECONDARY STRESS AND VOWEL EPENTHESIS IN SOUTHERN \\ BRAZILIAN PORTUGUESE
}

\author{
Tatiana Keller* \\ Evellyne Patrícia Figueiredo de Sousa Costa**
}

\begin{abstract}
Resumo: A observação de que o acento secundário ocorre na pauta pretônica, um dos contextos mais favorecedores para a ocorrência de epêntese, conforme análises variacionistas, como a de Collischonn (2002), e de que a epêntese cria uma sílaba a mais nessa posição parece indicar que possa haver uma correlação entre a incidência desse fenômeno e esse tipo de acento. Collischonn (1994) e Moraes (2003) identificam duas tendências em relação ao acento secundário em português: proeminência inicial e alternância binária entre sílabas fracas e fortes. Quando uma palavra tem número par de sílabas pretônicas essas duas tendências podem ser atendidas simultaneamente; o mesmo não ocorre quando o número de sílabas é ímpar. Neste trabalho, investiga-se a possibilidade de ocorrer mais epêntese vocálica em palavras com número ímpar de sílabas pretônicas para atender às duas tendências para a incidência de acento secundário e também analisa-se a localização desse acento em palavras com esse número de sílabas com e sem inserção vocálica. A amostra selecionada constitui-se de 8 entrevistas, pertencentes ao Banco de Dados VARSUL, realizadas na cidade de Porto Alegre com informantes do sexo masculino e feminino, nas faixas etárias mais de 50 anos e menos de 50 anos e escolaridade superior.
\end{abstract}

Palavras-chave: Acento Secundário; Epêntese Vocálica; Português Brasileiro; Análise Fonológica.

\begin{abstract}
The fact that secondary stress occurs in pretonic syllables, one of the most favorable contexts for vowel epenthesis in Brazilian Portuguese, as pointed by sociolinguistics analysis, such as Collischonn (2002), and the observation that epenthesis creates a new syllable in this position seems to indicate that there may be correlation between this phenomenon and this type of stress. Collischonn (1994) and Moraes (2003) identify two trends in relation to the secondary stress attribution in Portuguese: initial prominence and binary alternation between strong and weak syllables. When a word has an even number of pretonic syllables these two trends can be met simultaneously; the same does not occur when the number of syllables is odd. In this paper, we investigate the possibility to occur more vowel epenthesis in words with an odd number of pretonic syllables to meet these two trends and also analyze the location of
\end{abstract}

\footnotetext{
* Doutora em Linguística Aplicada pela Pontifícia Universidade Católica do Rio Grande do Sul (PUCRS). Professora Adjunta do Departamento de Letras Vernáculas da Universidade Federal de Santa Maria.

** Doutora em Linguística Aplicada pela PUCRS. Professora Adjunta do Departamento de Letras Clássicas e Linguística da Universidade Federal de Santa Maria.
} 
secondary stress in words with an odd number of pretonic syllables with and without vowel insertion. The sample consists of 8 interviews, belonging to the VARSUL database, with higher educated male and female subjects from Porto Alegre below 50 years old and over 50 years old. Keywords: Secondary Stress; Vowel Epenthesis; Brazilian Portuguese; Phonological Analysis.

\section{Introdução}

0 acento secundário pode ser caracterizado como um acento à esquerda do acento primário que se realiza com uma menor saliência em relação a este, como observamos nas palavras jacaré, medicina, macarrão (a sílaba que o recebe está em itálico e a sílaba tônica está em negrito). Collischonn (1994) e Moraes (2003) identificam duas tendências em relação ao acento secundário em português: proeminência inicial e alternância binária entre sílabas fracas e fortes. Collischonn (1994) salienta a alternância binária como principal característica do acento secundário; Moraes (2003), por outro lado, verifica que a proeminência inicial é o padrão que mais se destaca. Não há consenso entre os dois autores no que diz respeito ao número de acentos secundários que podem ocorrer em um vocábulo: Collischonn (2003) prevê que possa ocorrer mais de uma proeminência secundária e Moraes (2003) admite apenas uma.

Quando uma palavra tem número par de sílabas pretônicas essas duas tendências poderiam ser atendidas simultaneamente, uma vez que o acento secundário pode incidir na primeira sílaba e também alternar-se entre uma sílaba acentuada e outra desacentuada (canibalizar); o mesmo não ocorre quando o número de sílabas é ímpar. Neste caso, apenas uma das tendências pode ser atendida: se o acento incidir na primeira sílaba, teremos uma sequência de sílabas desacentuadas (canibalização), se houver alternância entre sílabas fracas e fortes, a primeira sílaba ficará desacentuada (canibalização).

É importante ressaltar que, na visão de Moraes (2003), essas duas tendências poderiam ser atendidas ao mesmo tempo apenas quando a palavra tiver duas sílabas pretônicas. Em outras situações, apenas a proeminência inicial é identificada.

A epêntese vocálica caracteriza-se pela inserção, na fala, de um segmento vocálico (principalmente, a vogal [i]) entre dois segmentos consonantais, o qual não é registrado na

escrita. É o que ocorre em pronúncias como [pi'new] 'pneu', [adzivo'gadu] 'advogado' e 
[sigini'fike] 'significa'. Nesse processo, há a criação de uma nova sílaba cujo núcleo é ocupado pela vogal epentética e o ataque pela primeira das consoantes. Estudos variacionistas, como o de Collischonn (2002), têm mostrado que a epêntese é um fenômeno variável de alta aplicação na fala do sul do Brasil, especialmente em Porto Alegre com peso relativo de $0,63^{1}$.

O fato de o acento secundário ocorrer na pauta pretônica, um dos contextos mais favorecedores para a ocorrência de epêntese (de acordo com análises sob o enfoque da Teoria da Variação), e de a epêntese criar uma sílaba a mais nessa posição parece indicar que possa haver uma correlação entre a incidência desse fenômeno e esse tipo de acento. A análise de Collischonn (2002) identificou as seguintes taxas de aplicação e pesos relativos na ocorrência de epêntese levando em conta a posição da sílaba tônica: na pauta pretônica, a aplicação foi de $69 \%$ e o peso relativo 0,68 ; na postônica, a aplicação foi de $24 \%$ e o peso relativo 0,24 .

Neste trabalho, investiga-se a possibilidade de ocorrer mais epêntese vocálica em palavras com número ímpar de sílabas pretônicas para atender às duas tendências de incidência de acento secundário e também se analisa a localização desse acento em palavras com esse número de sílabas com e sem inserção vocálica.

A amostra selecionada constitui-se de 8 entrevistas realizadas na cidade de Porto Alegre com 8 informantes divididos nas seguintes células: 2 homens e 2 mulheres com mais de 50 anos; 2 homens e 2 mulheres com menos de 50 anos; todos com escolaridade superior. As entrevistas foram feitas entre 1998 e 1999 e fazem parte do banco de dados do Projeto VARSUL (Variação Linguística no sul do Brasil). As palavras selecionadas têm contexto para epêntese na posição pretônica, pois a pauta postônica é irrelevante para o estudo do acento secundário. E realizam-se com ou sem epêntese.

É importante frisar que, embora os dados que ora são analisados tenham sido coletados seguindo a metodologia da Teoria da Variação, esta não é uma pesquisa de cunho sociolinguístico.

\footnotetext{
${ }^{1} \mathrm{Em}$ análises variacionistas, considera-se que pesos relativos superiores a 0,50 favorecem a ocorrência do fenômeno, abaixo de 0,50 desfavorecem e em torno de 0,50 ficam no ponto neutro.
} 


\section{Referencial teórico}

\subsection{Acento secundário}

Ao contrário do acento primário, o acento secundário não é distintivo em português, ou seja, não há palavras que se opõem em virtude de sua localização. No entanto, existem evidências fonológicas e fonéticas para a sua realização. Citamos, a seguir, algumas delas. Câmara Jr. (2001 [1970]), por exemplo, não menciona explicitamente o termo acento secundário, mas admite que existam, em português, graus diferentes de acento. 0 autor diz ainda que as sílabas pretônicas são menos débeis do que as postônicas, o que sugere que estas sejam, de alguma forma, mais proeminentes do que aquelas.

Major (1985) afirma que no nível da palavra há dois graus de acento em português: a sílaba tônica porta acento primário e sílabas pretônicas portam acento secundário; sílabas postônicas não recebem acento. 0 autor verifica que as sílabas tônicas são mais longas, as postônicas são mais curtas e as pretônicas são intermediárias. Segundo o autor, em muitas línguas, a ausência de acento está associada à simplificação de estruturas silábicas - por exemplo, diminuição no número de segmentos possíveis, simplificação de grupos de consoantes ou mudança de uma sílaba pesada para leve. 0 português mostra grandes diferenças no padrão fonotático entre sílabas pretônicas, postônicas e tônicas: o maior número de combinações pode ocorrer em contexto tônico, um número um pouco menor em contexto pretônico e o menor número de combinações pode ocorrer em contexto postônico. De acordo com Bisol (2003), o sistema vocálico do português do Brasil apresenta um sistema de sete vogais que se manifesta plenamente em posição tônica e dois subsistemas átonos: um sistema de cinco vogais, que tem sua plenitude na pretônica, e um sistema de três vogais na átona final.

No que diz respeito à identificação de correlatos fonéticos do acento secundário no português brasileiro citamos as pesquisas de Gama-Rossi (1998), Arantes e Barbosa (2002), Moraes (2003) e Fernandes-Svartaman, Abaurre e González-López (2008).

Gama-Rossi (1998) observa que o correlato duração não é consistente para identificar a presença de uma alternância binária na implementação de acentos 
secundários, ao passo que a qualidade vocálica apresenta resultados robustos para essa alternância; por fim, a autora identifica que frequência fundamental (F0) apresenta índices estatisticamente significativos apenas para alguns casos. Arantes e Barbosa (2002) ao analisar duração verificam que não há alternância no que diz respeito a esse parâmetro entre unidades portadoras e não portadoras de acento secundário. Embora os resultados de Moraes (2003) não sejam conclusivos, os parâmetros acústicos associados a esse acento podem ser F0 ou a conjunção de duração e de intensidade. Fernandes-Svartaman, Abaurre e González-López (2008) abordam a relação entre a percepção do acento secundário por falantes nativos de português brasileiro e a identificação do correlato acústico intensidade possivelmente associado a esta percepção. A partir de modelamento estatístico, as autoras confirmam a hipótese de que a percepção de acentos secundários pelos falantes de português brasileiro pode estar relacionada não só à variação de intensidade associada às sílabas percebidas como portadoras deste tipo de acento, mas também à variação de intensidade associada às outras sílabas pretônicas que ocorrem no seu entorno, no âmbito da palavra prosódica.

De modo geral, esses trabalhos têm mostrado que não há resultados robustos relativos a correlatos acústicos específicos para a identificação do acento secundário.

Fernandes-Svartaman, Abaurre e González-López (2008) chamam a atenção para o fato de que a implementação do acento secundário não é categórica, podendo, por isso, ocorrer de modo variável, conforme os diversos modos de implementação do ritmo. A seguir, apresentamos as análises de Collischonn (1994) e Moraes (2003) que tratam das possibilidades rítmicas de ocorrência do acento secundário no português brasileiro.

Collischonn (1994) diz que há duas tendências para a realização de acento secundário: uma, de alternância binária entre sílabas fortes (s- strong) e sílabas fracas ( $w$ weak), como vemos em (1)

bi. ci. cle. ta cho. co. la. te

$\begin{array}{lllllllll} & \text { W } & \text { S } & \text { W } & \text { S } & \text { W } & \text { S W }\end{array}$ 
e outra, de proeminência inicial, em que a primeira sílaba, isto é, a sílaba mais à esquerda, de um vocábulo seja forte, como se observa em (2).

a. ba. ca. $x i$

S W $\quad$ W $\quad$ S

Em vocábulos com número par de sílabas que antecedem o acento primário, as duas tendências podem ser satisfeitas ao mesmo tempo, como (3) mostra:

co. mu. ni. ca. ti. vo

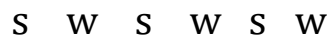

Já em vocábulos com número ímpar de sílabas antes do acento primário, essas tendências não podem ser, simultaneamente, mantidas, isto é, elas entram em conflito entre si e podemos ter duas possibilidades de estrutura rítmica, como vemos em (4a, b):

a) co. mu. ni. car

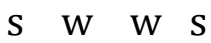

ou

b) co. mu. ni. car

$\mathrm{W} \quad \mathrm{s} \quad \mathrm{W} \quad \mathrm{s}$

Em (4a) não há alternância entre sílabas fracas e fortes, mas uma sequência de duas sílabas fracas. A tendência da primeira sílaba forte é satisfeita, mas a alternância fraco-forte não. Em (4b), por outro lado, a alternância é mantida, mas a primeira sílaba passa a ser fraca; ou seja, a tendência de alternância fraco-forte é satisfeita, ao passo que a tendência à primeira sílaba forte não é. 
Moraes (2003) analisou a percepção de cinco ouvintes acerca da realização de acento secundário a partir da fala de 4 informantes a fim de: (a) verificar a relevância desse acento para o português brasileiro; (b) definir sua localização e (c) descrever sua realização fonética. 0 autor elaborou um corpus composto por cinco grupos de quatro vocábulos cada um, de mesma base segmental, em que a localização prevista do acento secundário fosse variando, em consequência do deslocamento do acento lexical primário. Os grupos de vocábulos foram inseridos em duas frases-moldura que foram lidas e gravadas por quatro informantes.

Posteriormente, as frases foram ouvidas por cinco ouvintes que deveriam marcar todas as sílabas que, além das portadoras de acento tônico primário, sentissem, de alguma forma, como proeminentes na fala dos informantes.

Os resultados do teste de percepção indicam que dois padrões distintos se manifestam: o de alternância binária (formação de pés troqueus), caracteristicamente encontrado em 1 informante, e o da proeminência inicial (acento secundário recai na pretônica inicial), caracteristicamente encontrado em 3 informantes. Além disso, o autor verifica a ocorrência de apenas uma proeminência secundária em cada vocábulo.

\subsection{Epêntese vocálica}

O fenômeno da epêntese vocálica é a inserção, na fala, de um segmento vocálico entre duas consoantes, não registrado na escrita. Pode ser exemplificado por pronúncias

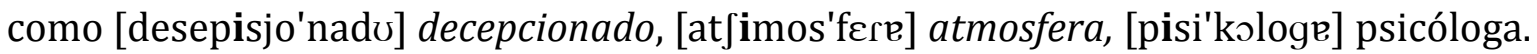

Consideremos a estrutura silábica do português (BISOL, 1999, p. 96) em (6):

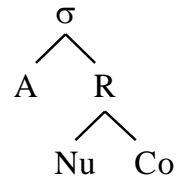


Conforme (6), uma sílaba consiste em um ataque (A) e em uma rima (R); a rima, por sua vez, consiste em um núcleo $(\mathrm{Nu})$ e em uma coda $(\mathrm{Co})$.

Em português nem todas as consoantes podem ocupar a posição de coda. As consoantes preferidas para ocupar essa posição estão ilustradas em (7).

/S/ - festa; pasta

/R/ - carta; morte;

/L/ - palma; golpe;

/N/ - campo; bomba; canto, mentira

Apesar de o português licenciar apenas os arquifonemas /S/, /R/, /L/ e /N/ como preferidos para a posição de coda, temos palavras que violam essa condição, como, por exemplo: infecção, mogno, objetivo, adquirir, atmosfera. Para evitar sílabas como essas, que não obedecem às condições de boa formação silábica do português, é que se insere a vogal epentética. Com essa inserção as consoantes que antes ocupavam posição de coda passam a ocupar posição de ataque.

Contudo, é importante ressaltar que a realização de epêntese não é categórica, ou seja, existe variação de pronúncias com e sem a inserção de vogal epentética. É o que análises no âmbito do projeto "A variação do fenômeno da epêntese vocálica no português do sul do Brasil" apontou (COLLISCHONN, 2000, 2002; KELLER, 1999; por exemplo).

\section{Metodologia}

\subsection{Objetivos e Hipóteses}

Neste trabalho, investiga-se a possibilidade de ocorrer mais epêntese vocálica em palavras com número ímpar de sílabas pretônicas para atender às duas tendências para a incidência de acento secundário e também analisa-se a localização desse acento em palavras com esse número de sílabas com e sem inserção vocálica. 
Tomando por base as duas tendências referidas por Collischonn (1994) e Moraes (2003), de que as sílabas de um vocábulo alternem de forma binária entre sílabas fortes e fracas e de que a primeira sílaba de um vocábulo seja forte, formulamos as seguintes hipóteses acerca da realização de epêntese e de acento secundário.

Cabe ainda dizer que essas hipóteses consideram a epêntese como uma estratégia de reparo de estrutura silábica marcada. Nossas hipóteses buscam explicitar a ideia de que o reparo de uma estrutura silábica malformada não deveria ter como consequência uma estrutura de acento marcada ou malformada.

Eis as hipóteses:

1) Considera-se que os vocábulos que tenham número par de sílabas antes do acento primário tendam a não apresentar epêntese, já que o acento secundário pode incidir na primeira sílaba, ao mesmo tempo em que é obedecida a alternância forte/fraco².

forma sem epêntese: a. dap. 'tei forma com epêntese: ,a. da. pi. 'tei ou a. da. pi. 'tei

A inserção de uma vogal aumenta o número de sílabas pretônicas, o que resulta num conflito entre as duas tendências acima apresentadas. Entendemos que, neste caso, seria melhor que não ocorresse inserção de vogal para atender as demandas rítmicas.

2) Considera-se que, em vocábulos com número ímpar de sílabas que antecedem o acento primário, a epêntese seja mais frequente; pois, com a inserção da vogal epentética, o número de sílabas do vocábulo aumenta e torna-se par, podendo o acento secundário incidir na primeira sílaba ao mesmo tempo em que as demais sílabas podem obedecer a alternância forte/ fraco.

\footnotetext{
2 Para evitar confusão com a grafia, a forma escolhida para a notação do acento primário é a apóstrofe

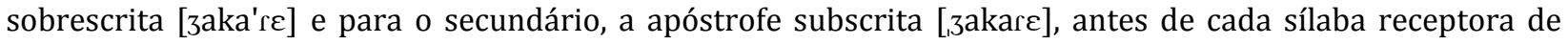
acento.
} 
(9)

forma sem epêntese: ,ad. mi. nis. 'trar ou ad. mi. nis. 'trar

forma com epêntese: ,a. di. ,mi. nis. 'trar

\subsection{Amostra}

A amostra selecionada para o presente trabalho constitui-se de oito entrevistas realizadas na cidade de Porto Alegre com informantes divididos nas variáveis extralinguísticas sexo, faixa etária e escolaridade. A distribuição dos informantes é a seguinte: 2 homens e 2 mulheres com mais de 50 anos; 2 homens e 2 mulheres com menos de 50 anos, perfazendo um total de 8 informantes. Todos têm grau de escolaridade superior. As entrevistas foram feitas entre 1998 e 1999 e fazem parte do banco de dados do Projeto VARSUL.

Na estratificação dos dados no âmbito do projeto "A variação da epêntese vocálica no português do sul do Brasil"(COLLISCHONN, 2000, 2002), havia o grupo de fatores extralinguísticos informante, em que se analisava o comportamento individual dos falantes. Para a presente amostra, esse grupo de fatores não foi selecionado como estatisticamente relevante nas análises sobre epêntese, o que indica que não haveria idiossincrasias entre os informantes.

\subsection{Corpus}

Foram selecionadas para a análise apenas palavras com contexto para epêntese pretônica que se realizam com ou sem epêntese, pois a pauta postônica é irrelevante para o estudo do acento secundário. Todas as palavras têm mais de uma sílaba precedendo o acento primário, pois não há possibilidade de realização de acento secundário com apenas uma sílaba antecedendo esse acento. 0 corpus do trabalho está ilustrado no Quadro 1. 
Quadro 1: Corpus analisado

\begin{tabular}{|lcc|}
\hline Formas-alvo & Realizações com epêntese & Realizações sem epêntese \\
psi.co.lo.'gia & 1 & 10 \\
tec.ni.ca.'men.te & - & 1 \\
obs.cu.ran.'tis.ta & - & 1 \\
psi.co.mo.tri.ci.'da.de & - & 2 \\
ex.pec.ta.'ti.va & - & 5 \\
sig.ni.'fi.ca & 2 & - \\
ad.mi.nis.tra.'ção & 7 & 4 \\
ad.vo.'ga.do & 9 & 4 \\
ab.so.lu.ta.'men.te & - & 2 \\
ad.qui.'rir & 2 & - \\
a.dap.'tar & - & 4 \\
at.mos.'fe.ra & - & 1 \\
pers.pec.'ti.va & - & 5 \\
in.fec.'ção & - & 2 \\
ad.mi.nis.'tra.das & 1 & - \\
ad.mi.nis.tra.'ti.vo & 4 & 4 \\
ad.mi.nis.'trar & 1 & - \\
\hline
\end{tabular}

A seguir, analisamos tanto as formas que confirmam quanto as formas que invalidam as hipóteses 1 e 2 . No caso das violações, outro aspecto também foi observado, qual seja a localização do acento secundário.

\section{Apresentação e análise dos resultados}

Após serem selecionadas, as palavras foram analisadas de oitiva, um procedimento metodológico bastante empregado pela Teoria da Variação. Todavia, o presente estudo não é uma análise de cunho variacionista.

Uma análise acústica poderia auxiliar para confirmar/desconfirmar a percepção das autoras em relação à ocorrência e à localização do acento secundário; contudo, esse é um ponto que carece discussão, pois ainda não foram encontrados correlatos acústicos robustos para a identificação do acento secundário. Essa é uma questão a ser investigada em trabalhos futuros. 
No entanto, trabalhos que levam em conta a percepção do ouvinte, como os de Moraes (2003) e Keller (2011), mostram que a concordância na identificação do acento secundário foi bastante alta, ou seja, a percepção do ouvinte pode ser considerada confiável para o tratamento do acento secundário.

Nesta seção, analisamos os dados com base nas hipóteses apresentadas anteriormente e tratamos também da localização do acento secundário em palavras com número par de sílabas pretônicas que apresentaram epêntese e palavras com número ímpar.

Hipótese 1: palavras com número par de sílabas pretônicas

Conforme a hipótese 1, esperávamos que os vocábulos com número par de sílabas antes do acento primário não apresentariam vogal epentética, já que as tendências de proeminência inicial e alternância entre sílabas acentuadas/desacentuadas podem ser atendidas ao mesmo tempo.

Os vocábulos atmosfera, adaptar, infecção e perspectiva com número par de sílabas antes do acento primário ocorreram sempre sem inserção de vogal epentética, o que confirma a hipótese. Vejamos os resultados no Quadro 2.

Quadro 2: Palavras com número par de pretônicas sem epêntese

\begin{tabular}{|lcc|}
\hline Formas-alvo & Realizações com epêntese & Realizações sem epêntese \\
at.mos.'fe.ra & - & 1 \\
a.dap.'tar & - & 4 \\
in.fec.'ção & - & 2 \\
pers.pec.'ti.va & - & 5 \\
Total & & 12 \\
\hline
\end{tabular}

Entretanto, os vocábulos significa e adquirir, que também têm número par de sílabas, ocorreram sempre com inserção vocálica, o que contradiz a hipótese, uma vez que, com inserção de epêntese, esses vocábulos ficam com número ímpar de sílabas e não podem ser satisfeitas, simultaneamente, as tendências rítmicas para a ocorrência do acento secundário. Observemos os resultados no Quadro 3. 
Quadro 3: Palavras com número par de pretônicas com epêntese

\begin{tabular}{|lcc|}
\hline Formas-alvo & Realizações com epêntese & Realizações sem epêntese \\
sig.ni.'fi.ca & 2 & - \\
ad.qui.'rir & 2 & - \\
Total & 4 & \\
\hline
\end{tabular}

Nessas duas palavras, o acento secundário localizou-se na segunda sílaba. Essa localização mantém a alternância entre sílabas acentuadas e desacentuadas, mas não atende à tendência de proeminência inicial, como se observa em (10).

si. gi. ni. 'fi. ca

a. di. qui. 'rir

As palavras administração, advogado e administrativo mostram comportamento ambíguo, pois ora ocorrem com epêntese e ora sem. Contudo, o número de ocorrências, com epêntese, que desconfirma a hipótese 1 , no que tange às palavras administração e advogado, é maior do que o número que a confirma. No caso da palavra administrativo, o número de ocorrências, com e sem epêntese é o mesmo, o que nos leva a considerar que essa hipótese também não pode ser confirmada, uma vez que não há favorecimento de realizações sem epêntese. As realizações dessas três palavras encontram-se no Quadro 4.

Quadro 4: Palavras com número par de pretônicas com e sem epêntese

\begin{tabular}{|lcc|}
\hline Formas-alvo & Realizações com epêntese & Realizações sem epêntese \\
ad.mi.nis.tra.'ção & 7 & 4 \\
ad.vo.'ga.do & 9 & 4 \\
ad.mi.nis.tra.'ti.vo & 4 & 4 \\
Total & 20 & 12 \\
\hline
\end{tabular}

Nos casos em que ocorre epêntese, ficando ímpar o número de sílabas pretônicas nas palavras administração e advogado, a localização do acento secundário segue a tendência de proeminência inicial, mas não de alternância binária fraco/forte. Observemos (11). 
(11)

,a. di. mi. nis. tra. 'ção

a. di. vo. 'ga. do

De modo geral, de acordo com os resultados para as palavras com número par de sílabas pretônicas, ilustrados no Quadro 5, a hipótese 1 não é confirmada, pois o número de ocorrências com epêntese e o número de formas sem epêntese, 24 e 26, respectivamente, é muito semelhante.

Quadro 5: Total de ocorrências com palavras com número par de pretônicas
\begin{tabular}{|lcc|}
\hline Formas-alvo & Realizações com epêntese & Realizações sem epêntese \\
sig.ni.fi.ca & 2 & - \\
ad.qui.'rir & 2 & - \\
ad.mi.nis.tra.'ção & 7 & 4 \\
ad.mi.nis.tra.'ti.vo & 4 & 4 \\
ad.vo.'ga.do & 9 & 4 \\
ab.so.lu.ta.'men.te & - & 2 \\
a.dap.'tar & - & 4 \\
at.mos.'fe.ra & - & 1 \\
pers.pec.'ti.va & - & 5 \\
in.fec.'ção & - & 2 \\
Total & 24 & 26 \\
\hline
\end{tabular}

Hipótese 2: palavras com número ímpar de sílabas pretônicas

Passemos à análise da hipótese 2 segundo a qual em vocábulos com número ímpar de sílabas antecedendo o acento primário a epêntese seria mais frequente, pois, com a inserção da vogal epentética, o número de sílabas do vocábulo aumenta e torna-se par, podendo o acento secundário incidir na primeira sílaba e também as demais sílabas podem alternar-se entre fortes e fracas.

Conforme o Quadro 6, os vocábulos administradas e administrar ocorreram sempre com a vogal epentética, o que confirma a hipótese 2 , uma vez que o aumento de uma sílaba 
na pauta pretônica propicia que as duas demandas rítmicas sejam satisfeitas. No entanto, o número de ocorrências, dois, é bastante reduzido.

Quadro 6: Palavras com número ímpar de pretônicas com epêntese

\begin{tabular}{|lcc|}
\hline Formas-alvo & Realizações com epêntese & Realizações sem epêntese \\
ad.mi.nis.'tra.das & 1 & - \\
ad.mi.nis.'trar & 1 & - \\
Total & 2 & \\
\hline
\end{tabular}

Nos vocábulos tecnicamente, obscurantista, expectativa, psicomotricidade e absolutamente, em que não há inserção vocálica, as duas tendências rítmicas não podem ser atendidas simultaneamente, o que contraria a hipótese 2. É importante ressaltar que o número de ocorrências (22) que não confirma essa hipótese é bastante elevado. Embora a palavra psicologia tenha comportamento ambíguo, pois ocorre ora com epêntese ora sem, os resultados também não confirmam a hipótese 2 , uma vez que o número de ocorrências sem epêntese (10) é muito maior do que o número em que ela não ocorre (1). Esses resultados podem ser vistos no Quadro 7.

Quadro 7: Palavras com número ímpar de pretônicas com e sem epêntese

\begin{tabular}{|lcc|}
\hline Formas-alvo & Realizações com epêntese & Realizações sem epêntese \\
obs.cu.ran.'tis.ta & - & 1 \\
psi.co.mo.tri.ci.'da.de & - & 2 \\
psi.co.lo.'gi.a & 1 & 10 \\
ex.pec.ta.'ti.va & - & 5 \\
Total & 1 & 18 \\
\hline
\end{tabular}

Nas palavras obscurantista, psicomotricidade, tecnicamente e psicologia, em que não há epêntese e o número de sílabas pretônicas é ímpar, o acento secundário localizou-se na primeira sílaba. Essa localização segue a tendência de proeminência inicial, mas não mantém a alternância entre sílabas acentuadas e desacentuadas, como podemos ver em (12).

„obs. cu. ran. 'tis. ta

„psi. co. mo. tri. ci. 'da. de 
,tec. ni. ca. 'men. te

psi. co. lo. 'gi. a

Apenas a palavra expectativa apresenta alternância entre sílabas acentuadas e desacentuadas, mas para isso ocorrer é preciso que a primeira sílaba fique desacentuada, como observamos em (13).

ex. „pec. ta. 'ti. va

De modo geral, o que (12) e (13) nos mostra é que houve preferência por manter a proeminência inicial.

Em suma, os resultados para as palavras com número ímpar de sílabas pretônicas, listados no Quadro 8, não confirmam a hipótese 2, pois o número de formas sem epêntese (19) é significativamente maior do que o número de ocorrências com epêntese (3). Esse fato nos faz pensar que não haja relação entre a atribuição de acento secundário e a incidência de inserção vocálica nos dados em análise.

Quadro 8: Total de ocorrências com palavras com número ímpar de pretônicas

\begin{tabular}{|lcc|}
\hline Formas-alvo & Realizações com epêntese & Realizações sem epêntese \\
psi.co.lo.'gi.a & 1 & 10 \\
tec.ni.ca.'men.te & - & 1 \\
obs.cu.ran.'tis.ta & - & 1 \\
ad.mi.nis.'tra.das & 1 & - \\
psi.co.mo.tri.ci.'da.de & - & 2 \\
ex.pec.ta.'ti.va & - & 5 \\
ad.mi.nis.'trar & 1 & - \\
Total & 3 & 19 \\
\hline
\end{tabular}




\section{Considerações finais}

Neste trabalho, investiga-se uma possível correlação entre acento secundário e epêntese vocálica com base na observação de que o acento secundário ocorre na pauta pretônica, um dos contextos mais favorecedores para a ocorrência de epêntese, e de que a epêntese cria uma sílaba a mais nessa posição. Conforme Collischonn (1994) e Moraes (2003), há duas tendências para ocorrência de acento secundário em português: proeminência inicial e alternância binária entre sílabas fracas e fortes. Quando uma palavra tem número par de sílabas pretônicas essas duas tendências podem ser atendidas simultaneamente; o mesmo não ocorre quando o número de sílabas é ímpar. Nesse caso, apenas uma das tendências pode ser atendida.

Dessa forma, analisamos a possibilidade de ocorrer mais epêntese vocálica em palavras com número ímpar de sílabas pretônicas para atender às duas tendências de incidência de acento secundário e também se analisa a localização desse acento em palavras com esse número de sílabas com e sem inserção vocálica.

De modo geral, de acordo com os resultados para as palavras com número par de sílabas pretônicas, ilustrados no Quadro 5, a hipótese 1 não é confirmada, pois o número de ocorrências com epêntese e o número de formas sem epêntese, 24 e 26, respectivamente, é praticamente o mesmo. Os resultados para as palavras com número ímpar de sílabas pretônicas, listados no Quadro 8, não confirmam a hipótese 2, pois o número de formas sem epêntese (19) é significativamente maior do que o número de ocorrências sem epêntese (3). Esses fatos nos fazem pensar que não haja relação entre a atribuição de acento secundário e a incidência de inserção vocálica nos dados em análise.

\section{Referências}

ARANTES, P.; BARBOSA, P. A. Acentuação secundária em Português Brasileiro à luz do modelo dinâmico do ritmo: um estudo piloto. Anais do I Congresso Internacional de Fonética e Fonologia/VII Congresso Nacional de Fonética e Fonologia. Belo Horizonte (MG), 2002.

BISOL, L. Neutralização das átonas. DELTA, São Paulo, v. 19, n. 2, 2003. 
Os constituintes prosódicos. In: . (Org.). Introdução a estudos de fonologia do português brasileiro. Porto Alegre: EDIPUCRS, 1999.

CÂMARA Jr, J. M. Estrutura da língua portuguesa. 33. ed. Petrópolis: Vozes, 2001 [1970].

COLLISCHONN, G. A epêntese vocálica no português do sul do Brasil. In: BISOL, L.; BRESCANCINI, C. (Org.) Fonologia e variação: recortes do português brasileiro (VARSUL). Porto Alegre: EDIPUCRS, 2002.

. A epêntese vocálica no português do sul do Brasil: análise variacionista e tratamento pela Teoria da Otimalidade. Letras de Hoje, v. 35, n. 1, p. 285-318, 2000.

Acento secundário em português. Letras de Hoje, v. 29, n. 4, p. 43-53, 1994.

FERNANDES-SVARTAMAN, F. R.; ABAURRE, M. B. M.; GONZÁLEZ-LÓPEZ, V. A. Acento secundário e intensidade em português brasileiro. Anais do VIII Encontro do CELSUL. Porto Alegre, 2008.

GAMA-ROSSI, A. Qual é a natureza do acento secundário no português brasileiro? CadernosCentro Universitário S. Camilo, v. 4, n.1, p. 77-92, 1998.

KELLER, T. Um estudo perceptual do acento secundário no português brasileiro. Revista do GELNE, v. 13, 2011.

O fenômeno da epêntese vocálica no português falado em Panambi e Blumenau. Cadernos do I.L. Porto Alegre: UFRGS, 1999.

MAJOR, R. Stress Rhythm in Brazilian Portuguese. Language, v. 61, n. 2, p. 259-282, 1985.

MORAES, J. A. de. A manifestação fonética do pé métrico. Letras de Hoje, v. 38, n. 4, p.147162, 2003.

Recebido em junho de 2014.

Aceito em outubro de 2014. 